\title{
Espacio cultural y cambio político. Los intelectuales catalanes y el catalanismo
}

\author{
JoRDI CASASSAS I YMBERT *
}

\section{DEFINICIÓN Y VALORACIÓN TEÓRICA DE UNA PROBLEMÁTICA GENERAL}

El intento de contribuir al análisis de las elites intelectuales ante el cambio político en la España del primer tercio del siglo xx desde el estudio del catalanismo podría llegar a pensarse algo casi fuera de lugar; o bien lo peculiar supera lo compartido, y por ello pierde parte de su interés el estudio conjunto; o, a lo "catalán" se le reconoce una cierta coherencia diferencial, subproducto de su reivindicada "autonomía nacional", y se le conserva cómodamente apartado y excluido, argumentando su querida autoexclusión; o, finalmente, a la formulación de una cultura política que tiene por eje central una tendencia centrípeta como sería el catalanismo, por lógica se le niega la participación en una dinámica estatal de conjunto, en la que precisamente pudiera considerarse un nacionalismo general y plural ordenador de los particularismos y de la convivencia política contemporánea.

La presente comunicación, con todo y rozar el ensayismo al querer abordar un tema tan general, hasta por su alcance cronológico, pretende poner de relieve algunos elementos referentes a la acción del intelectual en la etapa contemporánea que superen la referencia exclusiva y excluyente al "caso catalán".

\footnotetext{
* Universidad de Barcelona, Noviembre 1989.
} 
Para ello debemos partir de una serie de ideas generales que sin elevarlas aquí a teoría o a método pueden servirnos de punto de referencia para la valoración de elementos concretos más o menos conocidos. En primer lugar existe la consideración que debemos dar, desde el campo de la historia, al concepto «intelectual». La historiografía francesa ha puesto un énfasis extraordinario en el carácter liminar de la reacción de los intelectuales ante el «affaire Dreyfus»; el énfasis se ha puesto en el momento en que por vez primera el intelectual convierte el adjetivo en sustantivo identificador. Individuos intelectuales y su suma (el colectivo de) reaccionando como tales ante un momento de crisis general e intentando aportar soluciones que permitan, a todas las clases sociales, recuperar el rumbo perdido, apercibirse de la naturaleza de los «males» generales, reorganizar los elementos definitorios de la nación. Para el caso español (y podemos partir de su abstracción), esta «clase" individual o colectiva cumplirá esta misión ante la "crisis española del siglo XX" '.

Esta función moral (testimonio, cumplimiento o traición de una misión histórica) es evidente; así lo ha reflejado la floreciente historia anglosajona. Las sociedades contemporáneas urbanizadas presentan una tendencia natural hacia la existencia de movilizaciones de masas, a la institucionalización y la politización (codificación) de las actividades colectivas y de representación de los intereses económicos ${ }^{2}$. El intelectual es quien codifica estas nuevas actitudes y las sirve de forma cotidiana, convirtiéndose él mismo, su existencia y eficacia sociales, en un reflejo y varemo del paso de su sociedad de referencia hacia estas situaciones que identificamos con la modernidad ${ }^{3}$. Ante los momentos de gran crisis política, social, "vital», cultural, etc..., estos intelectuales asumen o pueden llegar

Puede destacarse como modelo de estudio, integrado en un proceso histórico concreto, Ory, Pascual-SirinelLi, F., Les intellectuelles en France, de l'Affaire Dreyfus à nos jours. París, A. Colin, 1986; también el intento de reflexión metodológica de SIRINELLI, J. F., "Le hasard ou la necesité?, Une histoire en chantier. L'histoire des intellectuels, Vingtiéme siècle: Revue d'histoire 9 (enero de 1986).

Desde la perspectiva de la historia intelectual, este tema ha sido trabajado por el norteamericano Polock, J. G. A., Virtue, Commerce and History. Cambridge University Press, 1985.

${ }^{3}$ El problema de la modernidad como estadio bien definido es más importante en la perspectiva anglosajona que, pongamos por caso, en la mediterránea que más nos incumbe. En esta última, acostumbrada a procesos donde modernidad y tradición se mezclan sin mucho conflicto, la modernidad alude a un estadio más cronológico que cualitativo: sin embargo, situados en el primer tercio del xx español, la actualidad que encierra el concepto modernidad necesita llenarse de contenido para el intelectual que quiere vivir en función del a-historicismo y la a-territorialidad que representa el nuevo territorio urbano. Vid. DAVIS, Margaret, "La Notión de modernité», Cahiers du xx siècle 5 (1975); también Habermas, J., "La Modernité, un projet inachevé", Critique 413 (octubre de 1981). También LeVAN-LemEALE, L., "La perception de la innovation chez les économistes français (1896-1939"), Revue Historique 550 (1984). 
a asumir protagonismos extraordinarios: ya sea por su resonancia socialtestimonial, ya porque representan una actitud de emergencia, en la que el intelectual sale de su cotidianidad para jugar un papel de orientador político ${ }^{4}$.

Para el historiador resultará fundamental esta consideración, en que la religiosidad de raíz ilustrada que valora el testimonio, el papel progresista emancipador y universalizante de la cultura que genera ese intelectual ( $y$ por tanto la consideración de la gran obra o aportación ideal cultural) ${ }^{5}$, cede importancia ante la consideración cotidiana de un intelectual puesto en relación con las grandes transformaciones de la etapa contemporánea. Su estudio lo situamos en la confluencia de la historia político-institucional, social y cultural, y rechazamos la consideración de una fecha concreta en que aparezca o pueda considerarse «inaugurado" su protagonismo. El estudio del sector de los intelectuales no puede dejar de ser profundamente histórico y en este sentido podemos darle un papel de primer orden en la aparición y primer desarrollo de la "contemporaneidad". Así pues, y en la necesidad de establecer una frontera en la que la referencia sea el intelectual que actúa en el primer tercio del siglo xx, hemos a aludir a la aparición de un sector progresivamente numeroso, urbanizado y profesionalizado que busca formas de organización propia, abandona los “totalitarismos" del pensamiento de fines del XVIII y principios del xIx, e intenta acercarse al poder (local o general) para explicarlo, consolidar los nuevos consensos que lo justifican, así como los elementos que van a permitir su normal perpetuación ${ }^{6}$.

Desde esta perspectiva, lo que más va a interesarnos es localizar (y determinar la forma de analizarlo) el papel que este intelectual colectivo

${ }^{4}$ Siempre seguirá útil la lectura aquí de BERLIN, I., Contra la corriente (Ensayos sobre historia de las ideas). México 1983; también Rebray, R., Le Scribe. Génere du Politique. París, Grasset, 1980; Sand, S., L'lllussion du politique. George Sorel et le débat intellectuel, 1900. París 1985; finalmente, MoriA, E., Autocritique. París, Julliard, 1959.

${ }^{5}$ El punto de arranque de este tipo de consideración debemos situarlo en ALEMBERT, D., Essai sur la société des gens de lettres et des grans (1753), y una de las quejas más clásicas a la renuncia del intelectual a ejercer esta misión de influencia profunda en BEODA, Julien, $L a$ tradition des clercs. París, Grasset, 1927.

${ }^{6}$ Apuntemos este tipo de evolución para el caso italiano, vista desde la perspectiva del intervencionismo intelectual, por ejempio en GiovanNiNi, C., La Cultura de la "Plebe". Miti, ideologia, linguaggio de la sinistra in un giornale d'opposizione dell'Italia Liberale (1868-1883). Milán, F. Angeli, 1984; la visión global desde la perspectiva italiana, por ejemplo en Livorsı, F., Tradizione, contrarivoluzione e Fascismi. Milán, F. Angeli, 1985. En este sentido una de las obras clásicas y capitales es la de Mosse, G. L., The Nationalization of the Masses. Political Symbolism and Mass Movements in Germany, from the Napoleonics Wars through the Third Reich. Nueva York 1974. 
juega en la sociedad, en genérico y por relación a la dinámica social concreta; $y$, complementariamente, la evaluación de este intelectual considerado como reflejo de las transformaciones que van produciéndose, de la trepidancia y tensión del cambio o, simplemente, como caja de resonancia de lo que ocurre. Así pues, al historiador de los intelectuales deberá preocuparle determinar, como paso previo, la intensidad histórica de las relaciones entre cultura y política que caracterizan la dinámica global del área que estamos considerando: la relación entre historia, política y vida cultural, la influencia de las ideas sobre la dinámica de los hechos, va a representar el punto previo a la hora de considerar una historia de las elites intelectuales. De todo ello, dependerá su prestigio o su relegación, el equilibrio entre la fuerza de las construcciones ideales y la dinámica del poder ${ }^{7}$.

De lo dicho hasta aquí se desprende que la referencia a la trayectoria, significación e intervención de este intelectual, por relación a un ámbito general como el del estado, sólo es válida cuando la dinámica se reduce a ideas, este ámbito estatal se convierte en poder, y del poder nos interesa, fundamentalmente, su voluntad y posibilidades de imponer un consenso ideológico, sancionado por la historia, cuyo reflejo más externo denominamos nacionalismo de estado. Para el caso francés, por ejemplo, podriamos referirnos a la tensa evolución y síntesis a través de las que se produce la imposición de un modo de vida urbano, burgués, industrial y competitivo; las características de este proceso llevarán a la máxima significación y representatividad el valor "cultura política", y conferirá a los responsables de su creación una significación ciudadana como ocurre en pocos países europeos ${ }^{8}$.

El proceso de la lenta popularización de una ideología donde se combina la vulgarización aplicada del sansimonismo con la idealización de una República reducida ya a puro símbolo, conferirá a los sectores intelectuales franceses un papel de primer orden por lo menos desde la

\footnotetext{
7 Este extremo ha centrado la reflexión de Gramscl, A., Gli intellettuali e l'organizzacione della cultura. Torino 1949, asi como la de Boввı, N., «Els intel.lectuals i el poder (1977»), Debat ( 6 de junio de 1979), págs. 7-29 y las indicaciones del mismo autor en, "Della fortuna del pensiero di Cattaneo nella cultura italiana", Rivista Crítica di storia della filosofia, abril-junio de 1970. Un intento de aplicación concreta, también referida al caso italiano tan relevante en nuestro esquema, puede verse en BIgURAN, M. (ed.), Instituzione e borghesia locali Nell Italia Liberale. Milán 1986.

${ }^{8}$ Vid. supra nota 1. Además para el inicio de este proceso, vid. Pozzl, Regina, Gli intellettuali e il potere. Aspetti della cultura francesa dell'Ottocento. Bari, De Donato, 1979. Asimismo para el final de nuestro período de referencia. SinINELLI, J. F., Khagneux et normaliens des anneés vingt. Histoire politique d'une génération d'intellectuels (1919-1945). París, Fayard, 1988.
} 
coyuntura de 1848. La reacción de los intelectuales ante el «affaire Dreyfus» puede ser considerada como un jalón más de esta trayectoria de largo alcance ${ }^{9}$. Los elementos que individualizan esta actuación de 18971898 , se derivan del hecho que ahora el intelectual busca un nuevo protagonismo ante la sensación de emergencia que le embarga: parece romperse el equilibrio establecido entre un poder supeditado a las necesidades regeneracionistas del post 1870-1871 y la posición de un entorno internacional en el que la presión imperialista deja poco espacio a las decadencias nacionales. Los «intellectuels" del cotidiano Le Journal son herederos de Renan, alumnos de la Exposición Universal de 1889 e hijos de aquel Víctor Hugo al que han tributado un funeral de unas magnitudes y significación simbólica sin precedentes ${ }^{10}$.

Con el arranque del siglo $x x$ el concepto de intelectual se diversifica en este tipo de áreas sudeuropeas con suma rapidez. Las transformaciones son tan rápidas que sorprenden traumáticamente a los pensadores, artistas, literatos o profesionales liberales. A todos ellos les resulta imposible interpretar una línea unitaria que englobe transformaciones vertiginosas que afectan desde las concepciones estéticas a las formas de pensar más colectivas, desde las sensibilidades sociales a la revalorización de lo individual y lo privado. Internamente, este intelectual en genérico se convierte en caja de resonancia de lo que sucede; progresivamente del caos. Pero aparentemente, desde la óptica externa cada vez más influenciada por las fuerzas del mercado, el intelectual se extemporaliza, con lo que refuerza su papel en la sociedad al tiempo que se convierte en un elemento molesto: la tendencia a constituir pequeños y sectoriales parnasos no dejará ya de crecer. Pero ello no puede despistar

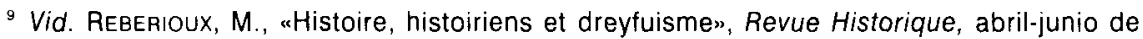
1976; Les escrivains et l'Affaire Dreyfus 2, PUF col. Université d'Orleans, 1983; también AuBert, $P$., "L'influence idéologique et politique de la France en l'Espagne de la fin du xixe siècle à la Premiére Guerre Mondiale (1875-1918"), España, Francia y la Comunidad Europea. Madrid, Casa de Velázquez/CSIC, 1989; CHARLE, Ch., "L'Affaire Dreyfus. Champ litteraire et champ du povoir: les écrivains et l'Affaire Dreyfus", Annales XXXII (1977); JAREÑo LÓPEZ, J., El affaire Dreyfus en España (1891-1906). Murcia, Godoy, 1981.

Vid. gran eco en la prensa francesa, en noviembre de 1899, de la inauguración del monumento "Triunfo de la República", con asistencia de la clase política, corporaciones y una masa de casi trescientos mil individuos. M. Cornely, redactor jefe de Le Figaro, llegará sin embargo a comentar que es el único monumento que no conmemora una victoria "nacional" frente al extranjero sino la "lucha y el triunfo de unos franceses contra otros franceses"; se refiere al triunfo de los dreyfuistas con el gabinete Waldeck-Rousseau. Luego, la crisis político-intelectual subirá de tono con la derrota dreyfuista en las elecciones municipales de París de mayo de 1900.

10 Vid. trabajos incorporados en NosA, P. (ed.), Les lieux de la memoire I. France, Gallimard, 1984. 
al historiador: se trata de la pervivencia de un sector intelectual-profesional y político sobre el que sigue descansando la vertebración, gestión, y perpetuación de los consensos que justifican el poder. Esta vertiente colectiva es la que más nos interesa reflejar como historiadores.

Situados en el área catalana, el potencial historicista y reivindicativo, que ya traduce, por ejemplo, la Renaixença romántica, va a convertirse en vehículo de fijación de una cultura política que va a hallar formas de imponerse como pauta de programas y movimientos de todo tipo y signo muy diverso ${ }^{11}$. La consolidación de esta tendencia va a llegar a su inequívoca identificación con el proceso de urbanización, industrialización, masificación y modernización que Barcelona dirige y personifica desde el inicio de la segunda mitad del siglo xIx. No puede extrañarnos, finalmente, que este tipo de identificación se prolongue más allá de las fronteras de Cataluña: la nueva cultura política que se asienta en esta área entra en rápida sintonía con las directrices y estrategias que priman, por lo menos, en el entorno inmediato europeo.

El personal encargado de pensar todo esto es el intelectual, entendido ya como colectivo. Así pues, consideramos intelectual a todo el que piensa, al margen de la solidez y la originalidad de lo que ha pensado, y que al tiempo que piensa dispone de un conducto para hacerse oír en colectivos más o menos numerosos. Las quejas referidas a la vulgarización democrática que ello implica y comporta como tendencia irreversible (Yxart, J. Letamendi, etc...), sólo hacen que evidenciar la aparición de un sector, de un momento en que su especialización y profesionalización sólo afecta aún a pequeños núcleos ${ }^{12}$. Pero la tendencia a la profesionalización se ha iniciado. Es por ello que personalmente aludimos al binomio intelectuales-profesionales, en tándem del que tienen conciencia los propios protagonistas porque, al margen de ello, van asimilándose de manera irremisible: en el plano formativo, en la coincidencia en las mismas asociaciones y academias, en el de los intereses políticos, etc... ${ }^{13}$.

"Un intento de realizar una visión globalizadora de la "Renaixença" catalana en RovirA । VIRGILI, Els corrents ideològics de la renaixença catalana (1947). Barcelona, Barcino, 1966. También en VALENTI FIOL, E., y finalmente, JoRBA, M., Manuel Milà i Fontanals i la seva època. Barcelona 1984.

12 La repulsa a las consecuencias culturales de la umasificación» YXART, J., El arte escénico en España (1894-1896) (ed. facsímil). Barcelona, Ed. Alta Fulla, 1987; también MarRart, R., José de Espronceda et son temps. Litterature, société, politique au temps du romanticisme. Francia 1974; el estudio algo "demodeé» de NowwER, E. The Artist as Politican. The Relationship Between the Art and Politics of the French Romantics. Washington 1984. Finalmente, Lissor. GUES, Y. (ed.), Realismo y naturalismo en España en la segunda mitad del siglo XIX. Barcelona, Antropos, 1988. Una visión general en Bıools, M., The Age of the Masses: Ideas and Society in Europe since 1870. Penguin 1977.

${ }_{13}$ De la abundante literatura sobre la profesionalización contemporánea podemos destacar 
Apuntemos, finalmente, como el estudio de la producción media de este sector, sobre todo cuando se le contrasta con los grandes techos de preocupaciones de época, es el único que puede darnos sentido a las obras más singulares y de mayor personalidad y hasta universalismo. A pesar de que no sea éste el lugar de entrar en detalles, podrá servir el ejemplo de Valentí Almirall, quien entre 1882 y 1885 piensa y en 1886 finalmente publica una de estas obras más singulares dentro de la historia intelectual del catalanismo, Lo Catalanisme (en 1902 él mismo la traducirá y publicará en castellano) ${ }^{14}$. La "singularidad" de esta obra descansa en su extensa justificación de una alternativa democrática en la que el catalanismo se presentaba como sinónimo de progresismo y apertura de miras, $y$, en el fondo, como la moralidad que libremente liga al individuo con su comunidad. A distancia, el libro de Almirall justifica el tortuoso camino de concreción de un nacionalismo de izquierdas. Pero ello no puede hacernos olvidar el contrapeso o lastre coyuntural del libro; entonces nos apercibimos de su carácter relativamente anacrónico, de su inclusión en un tipo de obras de intención regeneracionista que se están produciendo en los sectores en que se mueve Almirall desde fines de los setenta (A. de Bofarull, S. Santpere i Miquel, etc...) ${ }^{15}$. Implícitamente, este autor va a reconocerlo en 1897, cuando sitúe su obra por relación a los valores ya superados que habían servido en el marco de los grandes enfrentamientos doctrinales de los sesenta ${ }^{16}$.

ThuiLlier, G., Bureaucratie et bureaucrates en France au xIX siècle. Génova 1980; LEGENDRE, P., "Les maitres de la loi. Étude sur la function dogmatique en regime industriel", Annales 3 (mayojunio de 1983); LÉONARD, J., Les médecins de l'Ouest au xixé siècle (tesis). París 1978, 3 vols.; MARIN, M., "Journalistes parisiens et notoriéte (vers 1830-1870"), Revue Historique 539 (julioagosto de 1981); para el caso catalán: GarRABOU, R., Enginyiers industrials, modernització econòmica i burgesia a Catalunya (1850 inicis $s$. XIX). Barcelona, L'Avenç, 1982; SOLÁ MORALES, I. de, Origens de l'Escola d'Arquitectura de Barcelona; vv. AA., Elies Rogent i la Universitat de Barcelona. Barcelona 1988; JARDi, E., Historia au Col.legi d'advocats de Barcelona (2 vols.). Barcelona 1989.

14 Vid. Jutglar, A., "A manera de presentación, Almirall, V., Lo Catalanisme (facsímil). Barcelona, Alta Fulla, 1978 (incluye prólogo ed. 1902); también Figueres, J. M., "Prólogo" a ALMIRALL, V., "Articles Polítics, Diari Català (1879-1881"), Biblioteca dels Clàssics del Nacionalisme Català 7. Barcelona 1984; la ubicación "mítica" de Almirall en RovIRA I VIRGILI, "Resum d'hitòria del catalanisme", BCNC 1. Barcelona 1983, y aun en CuCURULL, F., "Panorama del nacionalisme català. Ed. Catalans de París, vol. III, 1975. Una utilización equivocada de Almirall en LLOBERA, J.R., «La idea de Volkgeist en la formació de la ideologia nacionalista catalana», L'Avenç 63 (septiembre de 1983).

${ }^{15}$ Vid. del propio AlmiRall, V., "Aspecte polític i social del renaixement català. Cartes al meu amic C.". La Renaixença 15 (1985); también España tal como es. Madrid, seminarios y ediciones, 1972 (estudio introductorio de A. Jutglar); VV.AA., El Memorial de Greuges i el catalanisme polític. Barcelona, Ed. La Magrana, 1986; una visión distorsionante, por asimilar mecánicamente idea a clase social en TrIas Vejerano, J. J., Almirall y los origenes del catalanismo. Madrid, Siglo XXI, 1975.

${ }^{16}$ Almirall, V., "Discurso presidencial. Ateneo Barcelonés (1896") en Casassas, J., L'Ateneu Barcelonès. Dels seus origens als nostres dies. Barcelona, Ed. La Magrana, 1986, págs. 68-91. 
Por lo que se refiere al catalanismo, hasta inicios de los setenta identificado con el radicalismo (por ejemplo de los federales), en el último cuarto del siglo xIX se recupera programáticamente como el elemento de amalgama de aquella cultura política con la que están identificados y que les asimila a sus congéneres italianos o franceses: la que justifica los programas que tienden a armonizar tradición y modernización, mundo rural con mundo urbano, en un intento global de dirigir los cambios que se están produciendo sin perder pie, buscando en el apoyo en la tradición y el pasado, en la regeneración, imprescindible, en el interés nacional, la concordia de clases, etc..., aquella doctrina y la estrategia con que piensan limar los peligros y tensiones que comporta la modernidad ${ }^{17}$.

\section{EL CATALANISMO Y LA DEFINICIÓN DEL ESPACIO POLITICO CATALÁN: ANÁLISIS DE UNA DINÁMICA}

Sin abandonar el orden esquemático, vamos a centrarnos ahora en algunos elementos que ayudan a caracterizar los períodos clave. Alrededor de Solidaritat Catalana (1904-1907), un período de definición confiada y casi eufórica del catalanismo político; tras la Semana Trágica (1909-1912), el replegamiento estratégico del conservadurismo y su primera definición de la alternancia «iberismo"-Catalunya hacia adentro" (según la expresión del poeta Joan Maragall, "Catalunya endins»); los dos períodos tienen un casi portavoz oficial en la revista La Cataluña. En relación a la crisis producida por el impacto de la Primera Guerra Mundial (1914-1917), la intelectualidad catalanista empezará a dar muestras de una alarma muy característica; tanto respecto a su voluntad de vertebrar una cultura política con posibilidades de proyección social real, como, internamente, al reflejar los impactos de los nuevos «ismos» que vienen a cuestionar las seguridades implícitas en el regeneracionismo novecentista de principios de siglo. La publicación La Revista, que dirije J.M. López-Picó, refleja a la perfección este primer revisionismo que dispone de una inicial plataforma de apoyo en la "Junta d'Afirmació Catalana".

Esta situación, agravada por la tensión de posguerra, agudizará la crisis ideológica y política interna del sector catalán de los intelectuales y profesionales y les hará evidente la irrupción de una situación de emergencia que les fuerza a actuar de nuevo. Este tipo de actuación de emer-

17 Bien adaptado a esta problemática, va a sobresalir la acción del sector Torrasiano del catolicismo catalán. Vid. RAMISA, M., Els origens del catalanisme conservador $i$ “La Veu de Montserrat» (1878-1900). Eumo, 1985. 
gencia, denominador común de multitud de actitudes colectivas e iniciativas que se dan en el entre-guerras europeo ${ }^{18}$, se traduce por un lado en la necesidad de crear partidos propios substitutivos de los preexistentes, a los que acusan de traición a los principios esenciales; en segundo lugar, periódicamente desengañados en su profundo y característico idealismo, intentando situarse por encima de los partidos, buscando crear plataformas o concretar acciones puntuales tendentes a orientar a los partidos y a la sociedad entera. Algunos intelectuales, individualizados al ser elevados a una más o menos permanente representatividad nacional, llegarán a ejercer esta función a título personal ${ }^{19}$.

Concretando en acciones colectivas fáciles de aprehender e integrar en un esquema único, se observa un proceso de reconstrucción política, que alcanza de fines de 1921 a mediados de 1923, y que se concreta en la formación de Acció Catalana y de la Unió Socialista de Catalunya. Más tarde, cuando la erosión provocada por la política represiva de la dictadura primorriverista parezca estar acabando con la normal vida política e institucional en que se desenvolvian estos intelectuales (y situar la cultura catalana en el primarismo tenso de las actitudes de resistencia), nuestros protagonistas van a intentar imponer como otra de las claves de su particular y sectorial estrategia, la búsqueda de aquella influencia general y el acuerdo extrapolítico con las elites intelectuales españolas (1927-1931), orientado a definir las bases de un nuevo período constituyente y, más allá, la definición superior de la nueva cultura política que lo deberá justificar $^{20}$. La suma de los años que acabamos de destacar en los apartados

18 Podemos referirnos entre otros, a los grupos de "L'Effort", al titulado "Une generation realiste", a la "Union Latine", etc., generalmente identificados como juventudes que reaccionan ante el desorden e ignorancia impotente heredados del periodo anterior. Vid. LUCHaiRE, Jean, Une generation réaliste. París 1929.

19 Para el caso catalán se resalta frecuentemente la referencia a la ejemplaridad de J. Maragall. Pero en estos años iniciales del siglo xx no podemos olvidar otros casos, como el de $\mathrm{J}$. Alomar o el menor de don Ruiz entre la juventud republicana de antes de la Semana Trágica. Vid. Navarro, E., Historia critica de los hombres del republicanismo catalán. Barcelona 1915; también JARDi, E., Quatre escriptors marginats. Barcelona, Curial, 1985.

${ }^{20}$ Resulta carismático el caso de J. Estelrich, por ejemplo, con Catalunya Endins. Barcelona 1930. El momento politic. Barcelona, Publicacions de les Juventutus Nacionalistes de Catalunya, 1930 , en los que se aprecia una superación coyuntural del veredicto avanzado por CAMBÓ, $F$., El problema català i els problemes espanyols. Barcelona, Imp. La Veu de Catalunya, 1923. Para los contactos entre la intelectualidad catalana y castellana en la crisis de la dictadura BASSOLAS, C., La ideología de los escritores. Literatura y política en la Gaceta Literaria (1927-1932). Barcelona, Fontamara, 1975; GIMÉnEZ CABALLERO, E., "Cataluña ante España", Cuadernos de la Gaceta Literaria 4 (1930); también VENTALLO, J., Los intelectuales castellanos y Cataluña. Barcelona, Galba, 1931. Para los contactos de la intelectualidad catalana con el Comité Revolucionario en enero-febrero de 1931 CASASSAS, J., Jaume Bofill i Matas (1878-1933). Barcelona, Curial, 1980 , págs. $320-347$. 
anteriores apenas supera la mitad del que completa nuestro período de referencia. Con todo, esta limitación no es suficiente para ocultarnos dos hechos de gran interés en nuestro esquema.

En primer lugar, y a pesar de que la responsabilidad intelectual-profesional en la creación del regeneracionista "catalanismo político" sea total, la constatación del relativo fracaso de su intento vertebrador de una política estable en los planos institucional y electoral, y que además fuera reflejo fiel y real del proceso de crecimiento y modernización urbanos, así como de una cierta conexión con los intereses de los grandes sectores que protagonizan este crecimiento: la patronal y el proletariado organizado de manera muy especial ${ }^{21}$. Paralelamente, y en segundo lugar, la constatación igualmente objetiva de como en todos los grandes momentos de crisis que incluye nuestro período (frecuentes y crecientes en intensidad) el catalanismo reaparece como el principal elemento de representatividad y cohesión políticos; y, progresivamente, como elemento básico de relación con la intelectualidad castellana, así como en uno de los más relevantes de la acción moral-ética y política con que quiere identificarse la intelectualidad española en el tenso proceso que le lleva de las primeras reacciones frente a la crisis mundial de entre-guerras al planteamiento de la Segunda República ${ }^{22}$.

\section{a) Regeneracionismo novecentista y catalanismo antes de 1914}

El impacto de la crisis finisecular, muy especialmente el de la colonial, como se sabe va a resultar decisivo para la fijación de los nuevos comportamientos públicos de las elites catalanas más directamente vinculadas con el catalanismo. Aquí no podemos superar la exposición de las líneas más generales; sin embargo, tampoco podemos olvidar que estas elites no representaban un núcleo homogéneo, sino que se agrupaban en diversas tendencias, círculos, editoriales e institucionales muy variadas. Con todo, desde fines de los ochenta venía siendo habitual diferenciarlos entre los radicales partidarios del retraimiento electoral apolítico, y los partidarios de la intervención; claro que hasta 1895-1901 este pleito había sido más teórico que práctico, puesto que nadie en Barcelona pensaba tan

${ }^{21}$ La tesis de la Lliga Regionalista como partido catalán de los industriales gozó hace un tiempo de gran predicamento. Así, por ejemplo, RocA, F., Política econòmica i territori a Catalunya (1901-1939). Barna, Ketres, 1979; también HARRiSON, J., "La gran indústria i el fracàs del nacionalisme català de dreta", Recerques 7 (1978), págs. 83-98.

${ }_{22}$ Un intento de comprensión de este esquema visto "desfe fuera" en Hina, Horts, Castilla y Cataluña en el debate cultural (1714-1939). Barcelona, Península, 1986. 
siquiera en la posibilidad de un enfrentamiento exitoso a las estructuras políticas caciquistas ${ }^{23}$.

A pesar de estas divisiones internas, a menudo recalcitrantes en un ambiente reducido y en unos medios intelectuales, más estrechos que aquellos otros que Sartre no dudaría en caracterizar por los efectos nocivos de su menudez intrínseca, existen unos pocos elementos denominador común sobre los que va vertebrándose la estrategia global del catalanismo. En primer lugar, el reconocimiento de que los techos mundiales con los que debía confrontarse este catalanismo de fines de siglo sólo podían venir determinados por los principios que los «modernos sociólogos" aplicaban al análisis y dirigismo de las sociedades occidentales contemporáneas ${ }^{24}$. Se trataba de asumir, como convicción irrenunciable, la premisa de que el catalanismo era sinónimo de modernidad y por ello diferenciaba Cataluña del resto de España, generalmente atrasada y poco en sintonía con las estrategias que regían la evolución continental. No es extraño, pues, que en lo concreto este catalanismo finisecular quisiera distanciarse del regeneracionismo que invadía la política oficial española a raíz del desastre colonial, un regeneracionismo al que no dudan en acusar de cortina de humo para evitar las reformas que realmente necesitaba el país ${ }^{25}$.

En segundo lugar, se afianza definitivamente la idea de que el nacionalismo es el único punto de confluencia "natural» entre la esencia tradicional e histórica que identifica "el alma nacional», y la moral colectiva mejor adaptada a las grandes tensiones que identificaban las modernas sociedades de masas, altamente urbanizadas e industrializadas. Así pues, este nacionalismo ha pasado a convertirse en una moralidad con altas

${ }^{23}$ La literatura al respecto es abundantísima. ALIBERG, R., “Com s'enssorrà el caciquisme a Barcelona i s'implantà de fet el sufragi universal a Espanya", La Veu de Catalunya, 12 de mayo de 1936. Destaquemos también como precedente Verdaguer Callís, N., La primera victòria del catalanisme. Barcelona 1919; MARTOS ONEALE, J., Peligro nacional. Estudios e impresiones sobre el catalanismo. Madrid 1901 (en colaboración con Julio Amado); las impresiones que da Cambó, F., Memòries (1896-1936). Barcelona, Alpha, 1981; o elementos concretos como los que evidencia Puy i Juanico, J., Alfons Sala i Argemí. Industrial i Polític (1836-1945). Terrassa 1983. Se llegó a aludir a Cataluña como oasis político-electoral en el sur de Europa; vid. DURAN I VENTOSA, LI., "El catalanisme i les eleccions", Le Veu de Catalunya, 1 de febrero de 1905.

${ }^{24}$ Este es el argumento inicial y subyacente en la serie que publica MARTí I JULIÁ, D., “Evolució del catalanisme", La Renaixença, 6, 10, 13 y 17 de diciembre de 1898

${ }_{25}^{25}$ La formulación del regeneracionismo catalán funisecular puede situarse en el periodo 1877 (textos de A. Sampere y de A. Bofarull) -inicios de los noventa. Para la evolución del regeneracionismo hacia posturas nacionalistas conservadoras vid. CASASSAS, J., Pensamenent i regeneracionisme en la Catalunya de finals segle XIx. Gerona, ponencia de "ll Jornadas de Filosofía Catalana, siglo xıx», Universitat Autònoma Barcelona, abril de 1989. 
posibilidades de traducirse en estrategia concreta, una de las pocas que dice no excluir nada ni a nadie, que se preocupa orgánicamente del problema más local al tiempo que de los más generales y que afectan hasta la misma concepción del Estado ${ }^{26}$. No en vano una de las grandes polémicas que afectan internamente este catalanismo finisecular va siendo la acusación entre "derechas" e "izquierdas" respecto al grado de sensibilidad que muestran hacia los grandes problemas definitorios de la dinámica mundial; o, por el contrario, hacia una dimensión trasnochada, ruralizante y casera que piensan va a convertir inefablemente a este catalanismo en patrimonio exclusivo de nostálgicos y sabios de pueblo ${ }^{27}$.

Claro está que en el fondo de polémicas como la que acabamos de citar no existen únicamente los apriorismos ideológicos; de la misma manera podemos asegurar que no se trata aquí del reflejo de los intereses de sectores marginales que se resisten a la desaparición de las viejas formas de vida en confrontación violenta con los sectores más modernos de la sociedad. Los compromisos más característicos arcaicos, identificados en un tiempo con el romanticismo conservador de los primeros Juegos Florales, se había diluido en la acción corporativa y pública que llevan a cabo los intelectuales catalanes desde los inicios de la Restauración, en función de Barcelona de una forma casi exclusiva: la existencia de un determinado lenguaje arcaizante no puede desorientarnos al respecto ${ }^{28}$.

En el fondo, lo que venía planteándose era la posibilidad de que este catalanismo hallase la formulación política positiva que le permitiera cons-

${ }^{26}$ Esta visión de un nacionalismo historicista y de síntesis ha sido trabajada para el caso germánico con gran profusión. Vid. Mosse, G. L. supra nota 6. También RoHL, J. G. G., From Bismarck to Hitler (The problem of Continuity in Germain History. J. Longman 1970; BaUM, Rainer C., The Holocaust and the German Elite. Genocide and National Suicide in German (1875-1945). Londres 1981; Weimer ou l'explosión de la modernité (actas). París, Ed. Anthorpos, 1984; ConNI, G.-SCHIERA, P. (eds.), Cultura politica e societá borghese in Germania fra Otto e Novecento. Boloña, II Mulino, 1986; finalmente, CervelLI, I., La Germania dell'Ottocento. Un caso di modernizzacione conservatrice. Roma, E. Riuniti, 1988.

${ }^{27}$ El modernismo se situó en esta disyuntiva cuando intentó reflexionar sobre la «realidad de Catalunya"; así, muy especialmente, los trabajos de Jaume Brossa en L'Avenç de 1892-1893. Vid. CACHo, V. (ed.), "Els modernistes i el nacionalisme cultural. Antologia», Biblioteca dels Clàssics del Nacionalisme Català 3. Barcelona 1984; Cadtellanos, J. (ed.), Els Modernistes. Barcelona, Empúries, 1988; VV.AA., El temps del modernisme. Abadía de Montserrat 1985; VV.AA., "L'Avenç i el modernisme», L'Avenç 125 (1989).

${ }^{28}$ Un ejemplo claro lo constituye la obra literaria, el doctrinarismo político y la actuación concreta de un A. Guimerà durante la Restauración. Vid. GuImerà, A., Cants a la Pàtria. Discursos. Barcelona 1906. Una explicación completa de todo ello en CASASSAS, J., Cultura i politica a la Catalunya del siglo xIx (Conservadors i catalanistes entre Escil. la i Caribdis) (en edición), especialmente cap. IX. 
truirse un espacio electoral propio $y$, a través de él, un afianzamiento social estable. Asi pues, la historia interna de este catalanismo, heredero del esfuerzo cultural romántico de principios del $x i x, y$ en el último cuarto de siglo patrimonio de los sectores intelectuales y profesionales barceloneses, no es otra que la que identifica su búsqueda de aquella extensión social ${ }^{29}$. Ésta, y no otra, es la razón por la que el nacionalismo catalán tendrá pobres teóricos, y sí estrategas de una fineza considerable... La definitiva fijación política de este nacionalismo reduce al mínimo la necesidad de teoria, y por contra precisa de una constante reformulación estratégica que le permita participar en la fijación de la cultura política y del mismo espacio cultural en los que se desenvuelve ${ }^{30}$.

El hecho de que como ocurre en Francia con la crisis boulangista, «panameña» o dreyfrusard (por citar las más relevantes), la crisis española desencadenada por la pérdida colonial no se salde con una crisis políticoinstitucional, y ni tan siquiera con una de partidista de una cierta envergadura, no va a sorprender a los políticos del nuevo catalanismo ${ }^{31}$. No en vano son herederos directos de aquellos otros conservadores sudeuropeos quienes a principios de los setenta habian ultimado unas constituciones políticas que subordinaban los principios a la competitividad regeneradora, o el fiel reflejo doctrinario del sistema liberal al relativo cinismo político que asegurase la imprescindible estabilidad parlamentaria integradora. Lo que más va a sorprender a estos jóvenes catalanistas que operan desde Barcelona, es la falta de vitalidad y el anacronismo con que la política oficial reacciona ante el desastre, su incapacidad de estructurar una «política de realidades» ${ }^{32}$.

Frente a todo ello, el catalanismo buscará su operatividad en la relación directa con los problemas que considera definitorios de la nueva situación catalana, española y universal. La fijación del denominado catalanismo político vendrá precedida y reflejará en todo momento la coyuntura más

29 Ello queda patente en la obra de Graell, J., Historia del Fomento del Trabajo Nacional. Barcelona, Tasso, 1911

30 Para las bases estratégicas de esta “imperiosidad" nacional vid. UCELAY DA CAL, Enrich, La Catalunya populista. Barcelona, La Magrana, 1982.

31 Coincidimos con el punto de arranque que centra Serrano, C.-Salaun, C. (eds.), 1909 en Espagne (essai d'histoire culturelle. Presses Universitaires de Bourdeaux 1988; pero consideramos necesario matizar algo el epicentrismo francés que refleja, en favor de la homogeneidad cultural europea de los años noventa siglo xix vid., por ejemplo, Mangonı, Luisa, Una crisi fine secolo. La cultura italiana e la Francia fra Otto e Novecento. Torino, Einandi, 1985.

${ }^{32}$ Asi, por ejemplo, las primeras colaboraciones de J. Pijoan en "La Renaixença" ("La feina de les màquines", "Lo sentiment de pàtria", "Del Territori», y recuérdese que Pijoan sería uno de los máximos responsables del inminente encuadramiento de las elites intelectuales para la realización del programa institucional-cultural del catalanismo político. 
general. Por relación a ella se enfrentan al regeneracionismo español, al tiempo que en ella encuentran los argumentos de su particular acción política. Todas las publicaciones periódicas del catalanismo, a fines de siglo y primeros años del actual van a dar una gran importancia a las secciones dedicadas al análisis y presentación de los casos europeos que justifican la aparición de este nacionalismo conservador finisecular ${ }^{33}$.

Ello se entiende, aunque sólo sea, por la naturaleza socio-profesional de los primeros dirigentes de este catalanismo: los representantes jóvenes de la elite cultural barcelonesa, los sectores intelectuales y profesionales herederos del largo proceso de la gestación inicial de este sector concretado a lo largo de la Restauración ${ }^{34}$. Su interés vendrá determinado por la necesidad de hallar aquella expresión política moderna y, viniendo de quien debía venir, no es extraño que se buscase la combinación de la acción de extensión y concienciación nacional con la que se habian identificado en el seno de asociaciones como la Unió Catalanista (1891), con la creación de un moderno partido de cuadros, al margen de las viejas estructuras caciquistas y pensando para actuar específicamente en el marco de la política local barcelonesa ${ }^{35}$.

No puede extrañarnos, por ejemplo, la pronta reacción de este catalanismo frente a las huelgas de diciembre de 1902, frente al mantenimiento de la inseguridad social $y$ al ascenso del republicanismo que lidera $A$. Lerroux ${ }^{36}$. Ya el 15 de enero de 1903 lanzan a la calle la revista Catalunya, dirigida por uno de los que serían considerados como novecentistas más destacados, Josep Carner; e inspirada por el núcleo más afín a Torres y Bages, agrupado en torno a instituciones como la "Lliga Espiritual de Ntra. Sra. de Montserrat" o como el "Cercle Artístic de Sant Lluc" ${ }^{37}$. La revista, que avanza ya algunos de los puntos centrales de lo que será la propuesta

${ }^{33}$ El responsable del comentario internacional de "La Veu de Catalunya" a fines de siglo era F. Cambó. En "La Reinaxença», de las Notes regionalistes a l'estranger se cuidaba Pelegrí Casades i Gramatxes, personaje de segunda fila pero muy ejemplar entre los individuos que gestionan el catalanismo finisecular: arqueólogo y erudito positivista, muy activo en los circulos de los Juegos Florales y del excursionismo «nacional».

${ }^{34}$ Una precisión de este proceso en CASASSAS, J., Intellectuals, professionals i politics a la Catalunya contemporània (1850-1920). Barcelona, Libros de la Frontera, 1989, especialmente caps. 2 y 3.

${ }_{35}$ Vid. Llonens, Jordi, L'aportació de Sebastià Farnés al Catalanisme. De l'Exposició a les Bases de Manresa (1888-1920). Universitat de Barcelona 1980; del mismo autor "Estudi Preliminar" a J. Narcís Roca i Farreras, "El catalanisme progressiu», Biblioteca dels Clàssics del Nacionalisme Català 2. Barcelona 1983.

${ }^{36}$ RIQUeR, Borja de, La Lliga Regionalista i la vaga general de Barcelona del 1902; más datos generales en NúNEZ, Rafael, El terrorismo anarquista (1888-1909), siglo xIX. Madrid 1985.

${ }^{37}$ Vid. JARDi, Enric, Historia del Cercle Artístic de Sant LluC. Barcelona, Destino, 1970. 
novecentista posterior, representa por un lado la manifestación pública de que se procede a la parcial integración y a la superación definitiva del pensamiento modernista; por otro, una plataforma que quiere ser unitaria y de captación de la juventud conservadora local, intentando romper las últimas barreras confesionales que servian a algunos para oponerse al eclecticismo posibilista del núcleo que dirigía Prat de la Riba ${ }^{38}$. Más allá y aupados por esta movilización, la convocatoria de 1903 del Primer Congrés Universitari Català. Este intento de "Catalanización" de la institución encargada de formar los cuadros de este sector que ahora se codifica políticamente, fracasará una vez más, y abrirá la búsqueda de una política alternativa (los «Estudis Universitaris Catalans») con la que se identifica la política novecentista ${ }^{39}$. Finalmente en abril del mismo año 1903, y siguiendo los primeros intentos de Marsans o N. Verdaguer por movilizar a un sector tan ligado al crecimiento urbano como era el de la dependencia mercantil, va a crearse "Centre Autonomista de Dependents del Comerç i la Indústria», muy ligado según filiación de los inspiradores, al catalanismo más radical de la Unió Catalanista ${ }^{40}$.

El conjunto de estas actividades venía justificado asimismo por el aparente cambio de tendencia política que afectaba al censo electoral barcelonés. Éste, en 1900 integraba a ciento dos mil quinientos setenta y cuatro individuos de los que en las elecciones generales de 1901 se habían abstenido de votar el 78,8 por 100 . Pero en las generales de 1903, la acción combinada del catalanismo y del republicanismo radical permitió reducir la abstención hasta la cota del 54,4 por $10{ }^{41}$. El hecho, era sinónimo de participación ciudadana y por tanto de capacidad integradora, hecho que afectaba a las elites intelectuales que dirigian el catalanismo por cuanto éste era, precisamente, uno de los elementos justificatorios de su acción política ${ }^{42}$. Pero el impacto de las huelgas de 1902 y la lentitud

${ }^{38}$ AULET, Jaume, "La revista "Catalunya" (1903-1905) i la formació del Noucentisme», Els Marges 30 (1984); y del mismo autor, "Jaume Bofill i Mates i la Congregació Mariana dels Jesuïtes de Barcelona (1894-1907'), en Estudis de Literatura Catalana en honor de J. Romeu Figueras. Abadía de Montserrat 1987.

${ }^{39}$ BosCH GImpera, P., La Universitat i Catalunya. Barcelona, Ed. 62, 1971. Els Congresos universitaris catalans. Catalanització $i$ autonomia de la Universitat. Barcelona, Undárius, 1977.

${ }^{40}$ El CADCl pronto se convirtió en un centro de promoción social, protección laboral y formación cívico-cultural; organizó un centro excursionista, clases nocturnas, una sociedad de mutuo socorro, ciclos de conferencia, unas "Escoles Mercantils Catalanes", etc. Para sus origenes es imprescindible la consulta de LLADONOSA, M., Catalanisme i moviment obrer: el CADCI entre 1903 i 1923. Publicacions de l'Abadia de Montserrat 1988.

41 Vid. BALCells, A.-CulLA, J. B.-M|R, C., "Les eleccionds generals a Catalunya de 1901 a 1923. Relació de resultats electorals de 1869 a 1899", Estudis Electorals 4 . Barcelona, Fundació J. Bofill, 1982.

${ }_{42}$ Desde los primeros años del siglo el problema de la integración humana se va a convertir en problema central de la política novecentista. Para una visión de conjunto resulta imprescin. 
con que el catalanismo lograba interesar a los sectores patronales (a pesar de los esfuerzos realizados por gente como Guillermo Graell), inclinará a la dirección de la Lliga Regionalista a pactar con un Comité de Defensa Social ultraconservador y católico, partidario de una acción contundente frente al desbordamiento social. El resultado de esta unión no podrá acarrear peores consecuencias políticas a la Lliga: la derrota electoral, y con la pérdida de la capacidad de influencia el retroceso sufrido en el proceso de acercamiento a la burguesía económica; la crisis interna (1904), con la escisión de la izquierda catalanista, la creación de la publicación El Poble Català (la alternativa a La Veu de Catalunya), y con ello, la "fuga" de importantes sectores de la intelectualidad catalanista. Finalmente, la vuelta a la situación urbana de tensión y descohesión: la abstención en las generales de 1905 vuelve a situarse en la cota del 71 por $100^{43}$.

La estructuración definitiva de lo que conocemos como novecentismo se enmarca y al tiempo intenta responder a este cúmulo de circunstancias. En este sentido representa un caso de la máxima significación para el análisis de la acción de las elites intelectuales ante el cambio político anterior a 1914. En 1911, el viejo modernista y ahora líder republicano catalanista Pere Corominas, no dudará en afirmar que «no es suficiente un ideal para dar vida a la Ciudad. Es necesario producir la concepción de una humanidad ideal que nos inflame a todos de amor" ${ }^{44}$.

Con el tiempo, en los medios cultural-políticos catalanes se afianzará una especie de coletilla satírica consistente en considerar algo o a alguien «más pesado que la prosa de Pedro Corominas». Ello no obsta, sin embargo, para que el citado intelectual y político haya identificado el tema de fondo. En su acción pública, el intelectual de la política novecentista debe definir e intentar imponer una moralidad colectiva (la shumanidad ideal") que centre la vida en el espacio cultural político en donde se mueve ${ }^{45}$. Esto es lo que intentaría realizar con una euforia inicial muy

dible la consulta de Termes, J., La immigració a Catalunya: Política i Cultura. Barcelona, Generalitat de Catalunya, 1983.

${ }^{43}$ Aun debe consultarse Molas, I., Lliga Catalana (vol. 1). Barcelona, Ed. 62, 1972; también PÉrez-BAstaRdas, A., Els republicans nacionalistes i el catalanisme: Albert Bastardas i Sampere (1871-1944). Barcelona, Ed. 62, 1987; finalmente, DuARTE, A., Pere Coromines: Del republicanisme als cercles llibertaris (1888-1896). Publicacions de l'Abadia de Montserrat 1988.

${ }^{44}$ Vid. Corominas, P., "De la Ciutat", en Almanach dels Noucentistes. Barcelona, J. Horta Editor, 1911 (la traducción es nuestra).

${ }^{45}$ En 1915 el mismo Corominas cifrará el fracaso del Catalanismo republicano en su manifiesta incapacidad para generar una accción de gobierno que sirviese para consolidar aquella "moralidad colectiva". Vid. Conominas, P., "Introducción" a E. Navarro, Historia crítica de los hombres del republicanismo catalán, op. cit., págs. 11-19. 
característica, un marcado sentido orgánico y una total voluntad generalizadora la corriente novecentista desde $1906^{46}$.

En la imposibilidad de aludir con detalle a los contenidos, nos referiremos exclusivamente a algunas de las circunstancias determinantes que fuerzan al intelectual-profesional catalán a realizar la actuación que englobamos bajo la etiqueta de "noucentisme". Nos referimos a una simple constatación de fechas. Si consideramos 1906 como la fecha de definición del novecentismo orsiano, no podemos dejar de notar como "coincide" con la publicación de La Nacionalitat Catalana de Prat de la Riba, con la elección de éste como presidente de la Diputación de Barcelona, con el arranque del movimiento de Solidaritat Catalana, con la formulación del programa maurista en Madrid, con la definición interna de la Lliga Regionalista, con la estructuración del que será el máximo portavoz del sector "La Cataluña» (inicia su aparición en 1907). Imposible, pues, pensar que se trata de una improvisación o de la acción de un intelectual más o menos aislado o, más allá, de una cuestión que atañe exclusivamente a la historia de las ideas ${ }^{47}$.

Así pues, consideramos imprescindible situar el tema en el plano de las estrategias de un sector de la sociedad que busca redefinir el espacio cultural-político catalán. Los elementos sobre los que las hace descansar son la Ciudad y el vivir "civilmente» ${ }^{48}$; la normalización y codificación; la asimilación de las corrientes que identifican el "novecientos", esto es, la sintonía con lo que ocurre por Europa; el equilibrio para evitar las tensiones y los extremismos doctrinarios; el catalanismo como normalidad colectiva de fondo; el clasicismo como matización general y como reafirmación puesto que la identificación con el mediterráneo enfrentado al norte desarrollado constituye una idea-fuerza, una trascendencia que confiere una cierta garra a las propuestas de estos sectores de intelectuales y profesionales generalmente idealistas en exceso ${ }^{49}$.

\footnotetext{
${ }^{46}$ VV.AA., El Noucentisme. Publicacions de l'Abadia de Montserrat 1987, ensayo destacado de aproximación polidisciplinar.

${ }^{47}$ A partir de 1909 la identificación de los primeros definidores del regionalismo novecentista con el amurismo se convertiria en un elemento de controversia interna de primer orden. Vid. TUSELL, J.-AVILÉS, J., La derecha española contemporánea. SUS origenes: El maurismo. Madrid, Espasa Calpe, 1986; también BOFILL, J., Pret de la Riba i la cultura catalana. Barcelona, Ed. 62, 1979; finalmente, CASASSAS, J., “Els Benplantats. La responsabilitat civil i política», en E. Ucelay da Cal (ed.), La joventut catalana al segle xx. Diputació de Barcelona 1987, vol. I, págs. 75-86.

${ }^{48}$ La elaboración de estrategias alrededor del hecho urbano ha adquirido capital importancia en el caso italiano desde el último cuarto del siglo xIX, con elementos comunes con el caso barcelonés. Vid. RosA, G., I/ mito de la capitale morale. Milán, Ed. Di Comunità, 1982; también Fıocca, G. (ed.), Borghesie imprenditori a Milano dall'Unità alla Prima Guera Mondiale. Bari, Laterza, 1984.

${ }^{49}$ A principios del siglo xx el modelo organizativo francés seguía estando presente en el
} 
No es de extrañar, pues, que todo este conjunto se haga desembocar desde el mismo 1906 en el imperialismo ${ }^{50}$. La revista Cataluña se convierte en el portavoz de este programa, con una tal prepotencia que antes de 1909 se permite integrar confinadamente las aportaciones de izquierdas y de derechas ${ }^{51}$. Tal es la confianza y la euforia que ha comunicado a los intelectuales barceloneses aquella coincidencia de factores: la disponibilidad de un partido de cuadros vertebrados, la nueva acción electoral-social que posibilita el movimiento de Solidaridad Catalana (en 1907 la abstención en Barcelona va a llegar a la cota más baja del período, 40,1 por 100 , y la inercia será grande: 1908,47 por 100; 1910, 42 por 100), una cierta sintonía con la "revolución desde arriba" maurista y la posibilidad de un cierto control institucional con la presidencia de Prat en la Diputación habrán bastado para ello ${ }^{52}$.

Euforia con paroxismo imperialista que, sin embargo, tenía los pies de barro en la denominada cuestión social, la gran preocupación novecentista para d'Ors y Prat, y hasta para el último de sus publicistas novecentista. Frente al primer empuje novecentista aparecen los primeros estudios sobre el movimiento obrero catalán del siglo xIx; las quejas contra el terrorismo urbano son constantes, las denuncias de la falta de capacidad integradora del crecimiento demográfico de la ciudad resultan hasta patéticas desde principios de 1907, y no será extraño que los hechos de la Semana Trágica produzcan el grado de terror suficiente como para producir cambios en profundidad en la estrategia del movimiento ${ }^{53}$.

horizonte de los intelectuales catalanistas más significados. Vid. JuNOY, J. M., "Al marge de la política i de l'estètica de Charles Maurras", Revista de Catalunya III, 21 (marzo de 1926); también Canals, S., "Prólogo" a Charles-Brun, J., El regionalismo (1911). Madrid 1918; Girardet, Le nationalisme français (1871-1914). París 1966; finalmente, THIÉBAUT, Flory, Le mouvement régionaliste français. Sources et développments. París, PUF, 1966.

${ }^{50} \mathrm{He}$ analizado este hecho en CASASSAS, J., "Un problema de relación nacionalismo-burguesia. El imperialismo en la teoria y la estrategia de E. Prat de la Riba", Estudios de historia social 28-29. Madrid 1984, págs. 169-179.

${ }^{51}$ El paralelo de "La Cataluña" con la florentina "La Voce" resulta espectacular; en ambos casos y en 1911, el inicial sincretismo eufórico va a derivar hacia una mayor cerrazón de las posturas conservadoras y aristocratizantes. Para el caso italiano vid. LUPERINI, Romano, Gli esordi del Novecento e l'esperienza della "Voce». Bari, Laterza, 1981.

${ }_{52}$ Este último factor ha sido destacado por aportaciones ya clásicas como Olivar Bertrán, R., Prat de la Riba. Barcelona, Aedos, 1966; AInAud, J. M.-Jardi, E., Prat de la Riba, home de govern. Barcelona, Ariel, 1973.

${ }^{53}$ A destacar Xènius, "Glossari», Final d'acte, "La Veu de Catalunya", 1 de enero de 1907; "Coses assenyalades", Barcelona Terrorista, "Empori» 1 (enero de 1907), pág. 50; SASTRE SANNA, M., Las huelgas en Barcelona, publicada en Barcelona anualmente; a destacar los correspondientes a 1906 y 1907 y como desde "La Veu de Catalunya" se recomienda insistentemente su lectura. Para las reacciones tras la Semana Trágica vid. D'OAS, E., en "Cicle de conferencies d'educació civil», Revista Anyal (CADCl). Barcelona 1911; más a distancia PRAT DE LA RIBA, "La Santa Continuación", La Cataluña 170-171 (7 de abril de 1911). 
A partir de 1909 el novecentismo produce una cierta escisión interna. Por un lado, los representantes de una visión globalizadora empeñados en ver el catalanismo como el elemento de cohesión social y político que debería permitir limar las confrontaciones sociales radicalizadas que amargaban cualquier intento de realizar una política civilizada de un regeneracionismo a la moderna. Esta corriente, que tiene un precedente difícil de integrar en la propuesta futurista de Alomar (1904) ${ }^{54}$, identificará a la izquierda catalanista y a una parte de los nuevos planteamientos que Martí i Julià está imponiendo en el seno de la Unió Catalanista, elementos que buscan en la reivindicación nacional un elemento imprescindible de cohesión social ${ }^{55}$.

Frente a ellos, un sector heterogéneo mayoritario, que políticamente a menudo hallamos identificado en el conservadurismo de la Lliga (y mayoritariamente con su teórica sección de juventudes y de hecho canal de encuadramiento de las elites intelectuales y profesionales conservadoras de la ciudad) ${ }^{56}$, quien de cara al interior de Cataluña vuelve a deslindar los campos de acción: de una parte una acción de catalanización y proselitismo, como mínimo peligrosa al no controlar la tensa dinámica social; de la otra, la edificación de un cierto estatalismo regional que conserva el atractivo de una forma al periódico enfrentamiento con un estado que no acaba nunca de cumplir con su deber, y que así puede presentarse como un elemento estratégico central, a la vez nacionalizador y reivindicativo ${ }^{57}$.

El catalanismo se ha asimilado finalmente a eficacia; es ya capaz, pues, de asimilar sin complejos la defensa de las raíces tradicionales e históricas (que ya hemos visto como sublima por la vía clasicista y mediterránea)

54 Vid. Alomar, G., El futurisme. Barcelona, L'Avenç, 1905 (texto de la conferencia realizada en el Ateneo barcelonés el 18 de junio de 1904). En septiembre-noviembre de 1907 será traducida al castellano en la revista Renacimiento; en 1908. Marcel Robin publicará una extensa recensión de la misma en el Mercure de France, la cual será silenciada por Marinetti y su Manifiesto de 20 de febrero de 1909.

${ }^{55}$ Vid. Colomer, Jaume, "L'aportació de D. Marti i Julià al catalanisme polític", en MARTi I JuLıȦ, Domènec, Per Catalunya $i$ altres textos. Barcelona, Biblioteca dels Clàssics del Nacionalisme Català, 1984.

${ }^{56}$ Vid. CASASSAS, J., «Els quadres del regionalisme. L'evolució de la Joventut Nacionalista de la Lliga fins al 1914», Recerques 14 (1983), págs. 7-32.

${ }^{57}$ La tendencia pro-gubernamentalista que afecta al regionalismo conservador sería denunciada por ALOMAR, "Controversias. La escuela filosófica del catalanismo", La Cataluña 15 (11 de enero de 1908). Esta tendencia potenciada por la campaña pro-Mancomunidad, reconvertiria el concepto pratiano de "Escola de la Lliga" (en el sentido de plataforma de civilidad política) en un mandato de especialización burocrática por el que la elite intelectual se ligaba al nuevo gubernamentalismo catalanista. Vid. BofILL, J., "La Joventut Nacionalista. L'expansió. La burocracia", La Veu de Catalunya, 1 de mayo de 1912. 
con el intervencionismo moderno; puede presentarse como una opción orgánica válida a un tiempo para gestionar con respeto el ámbito rural que representa de forma natural, y para dirigir el conjunto desde la «capitalidad" urbana, a la que considera haber dado todo su sentido a través de esta síntesis "camaleónica» que representa el programa político novecentista. Finalmente, este catalanismo novecentista, al buscar obsesivamente la concordia de clases ha acentuado extraordinariamente en las reflexiones teóricas y estratégicas lo que Jaume Bofill en 1907 no duda en denominar como "culturismo nacional", el valor pueblo nacional que supera las clases y justifica todas estas actuaciones ${ }^{58}$. Perfectamente adaptado a las dimensiones local, estatal y europea de fin de siglo, el catalanismo está avanzando las bases del pensamiento y la acción política de entreguerras ${ }^{59}$.

\section{b) Crisis de emergencia y acción intelectual tras la Gran Guerra}

¿Existe una generación con polo de acción-proyección en Barcelona, que refleja a un tiempo el impacto de la "Guerra del 14" y de la crisis de la Restauración? (la generación de los que en 1930-1931 sentarán las bases de la Segunda República aunque sea desde una ya inicial oposición a este régimen). En cualquier caso, la posible asimilación de preocupaciones entre los intelectuales que giran alrededor de organismos y publicaciones madrileñas y los barceloneses era normal en el plano de las ideas ${ }^{60}$. Pero al mismo tiempo, entre unos y otros aparecían elementos poderosos que debian modificar la proyección pública y política de las doctrinas y estrategias aparentemente compartidas, la acción que aquí más nos interesa analizar ${ }^{61}$.

En primer lugar, no podemos olvidar cómo en Barcelona disponían de un canal de actuación política bien constituido y aparentemente con un

${ }^{58}$ Vid. BoffIL, J., "Clasicisme Nacional» (conterencia de 22 de noviembre de 1907), en "L'Altre Concòrdia i altres textos sobre el catalanisme», Biblioteca dels Clàssics del Nacionalisme Català 4. Barcelona 1983

${ }_{59}^{9}$ Vid. ROdÉS, J. M.-UCELAY DA CAL, E., "Nacionalisme i Internacionalisme: "Els Amics d'Europa" i "Messidor"”; también UCELAY DA CAL, E., “El mirall de Catalunya: Models internacionals en el desenvolupament del nacionalisme i del separatisme català (1875-1923), ambos en Estudios de Historia Social 28-29 (Madrid 1984).

${ }^{60}$ Vid. "Dossier»: "Catalunya davant el món en guerra (1914-1919»), L'Avenç 69 (Barcelona marzo de 1984), especialmente MURGADES, J., "Repercussions de la guerra en la cultura" (págs. 74-79).

61 Vid. el ya clásico Diaz-PLAJA, F., Francófilos y germanófilos. Barcelona, Dopesa, 1973; también MAINER, J. C., Regionalismo, burguesía y cultura: «Revista de Aragón» (1900-1905), «Hermes» (1917-1922). Zaragoza, Guara, 1982. 
espacio propio (La Lliga Regionalista), muy superior al que podía brindar, por ejemplo, el reformismo de Melquíadez Álvarez en Madrid. En segundo lugar, buena parte de la elite intelectual-profesional catalana sensible a los cambios que se producen entre 1914 y 1918 , era ya personal directivo, de plantilla, eventual o potencial de las instituciones públicas generadas por el catalanismo y coordinadas desde abril de 1914 de forma oficial por la Mancomunitat ${ }^{62}$. Finalmente, en el juego de conceptos de la Gran Guerra aporta y remoza para el debate político-ideológico de entreguerras (cosmopolitano, unidad europea, pueblo, nación, estado, etc...) que duda cabe que la intelectualidad catalana tiene colocado un filtro intermedio que va a distorsionar si no los conceptos, como mínimo los análisis y sus posicionamientos públicos: se trata, claro está, del catalanismo, un concepto complejo que engloba a un tiempo la reivindicación frente al estado, la acción estatalista, con voluntad normalizadora e integradora, y a la aspiración intervencionista (imperialismo) fuera del estricto marco regional-nacional ${ }^{63}$.

Así pues, cuando este sector se sienta conmovido por los impactos producidos por la Gran Guerra, no podrá sorprendernos que los grandes temas que en el fondo van a discutirse sean los mismos que centraban sus preocupaciones de principios de siglo ${ }^{64}$. Los resortes siguen siendo, en primer lugar la presencia del factor europeo, como horizonte que moviliza al catalanismo, y que le permite presentarse como alternativa a la política española. En segundo lugar, un nuevo planteamiento del cual debe ser la actuación del sector intelectual-profesional en la vida pública catalana; más allá, que valor se confiere al catalanismo por relación a este tipo de actividad. Finalmente, y podría considerarse por la magnitud que alcanza, un tema inédito, la supeditación de esta acción a la respuesta casi visceral a una situación de emergencia que ven reflejada en todos los ámbitos de su existencia: desde la dimensión local catalana a la general de la «Europa en guerra civil», que más preocupa a un d'Ors, pasando por la que ocupa el estado, al que consideran el máximo agente de la radicalización social ${ }^{65}$.

62 Su inventario y descripción más completos en GALi, A., Història de les institucions $i$ del moviment cultural a Catalunya (1900-1936). Barcelona, Fundació AG, 1984 y ss. (20 vols).

63 Para las líneas generales del impacto de la Gran Guerra sobre la evolución del catalanismo político vid. CASASSAS, J., "La radicalització del catalanisme", L'Avenç 69 (1984), págs. 56-61.

${ }^{64}$ Ellos se desprende del número de presentación general de Cataluña que coordina la cúpula de la Lliga y la propia Mancomunitat. Vid. "Etude sur la nation catalane», Annales des Nationalités VI, 6-8 (1916).

${ }^{65}$ El tema, más allá de la simple reflexión intelectual, se convirtió en fundamento de las estrategias político-económicas del regionalismo desde el principio de la guerra, vid. CASALS, Muriel, "La burgesia industrial i la Guerra», L'Avenç 69 (1984), págs. 42-45; también CASASSAS, J., Jaume Bofill i Mates (1878-1933). Barcelona, Curiel, 1980, págs. 157-183. 
En Barcelona, la reacción de las elites intelectuales, con todo y no poder ser referida a una trayectoria única, refleja aquellas inquietudes generales en un in crecendo que nos lleva de 1915 a 1923. Estas actitudes deben partir de la constatación de algunos hechos capaces de intranquilizar a unos intelectuales que ven reaparecer el fantasma de la crisis mundial: los partidos políticos del catalanismo han entrado en crisis; la izquierda está fraccionándose, tras el fracaso electoral al que desemboca el Pacto de Sant Gervasi (1914), y la Lliga se ve agitada por un movimiento creciente de contestación interna. Paralelamente, la abstención se sitúa en la cota del 56,8 por 100 , y en 1920 en el 70,5 por 100 ; y, frente a todo ello, la demanda extraordinaria provocada por la guerra, que produce una avalancha - relativa pero sin precedentes - de mano de obra afluyendo sobre Barcelona, cambios significativos en los regímenes laborales y un inusitado incremento de la filiación sindical ${ }^{66}$. Finalmente, por más que se pregonasen sus éxitos, la acción institucional-cultural emprendida por el catalanismo novecentista no había tenido tiempo material de producir frutos relevantes, ni de consolidarse de forma incuestionable, para tranquilidad socio-profesional de estas elites. Todo ello sumado al pensamiento de crisis que llega a Europa, que en general tiende a invalidar actitudes críticas frente a las bases mismas sobre las que asentaba el período anterior, incluidas aquellas filias de unas patrias identificadas en el fondo con unos estados que eran corresponsables de la Gran Crisis $^{67}$.

Las principales líneas de actuación que se abrieron en este nuevo período de desequilibrios responden, además, a un cúmulo de preocupaciones que iban a afectar específicamente al sector intelectual-profesional barcelonés. De esta forma, no podemos dejar de notar como el mismo diciembre de 1914 se ponen en marcha plataformas que, como la citada "Junta de Afirmación Catalana", reunen destacados intelectuales de derechas e izquierdas, a la búsqueda de una mayor fluidez en la política del catalanismo, de una recatalanización general de la sociedad catalana, y de una "humanización" de las actividades públicas y políticas del país ${ }^{68}$. Otras plataformas podrán ser la aparición de "La Revista" o la del

${ }^{66}$ La necesidad de adecuar los comportamientos políticos a esta situación en el fondo va a mover los grandes posicionamientos de F. Cambó. Así, por ejemplo, La crisi social de Catalunya. Santiago de Chile, Germanor, 1920; también La crise mondiale et la Conférence de Genes. París 1922 .

67 Vid. Puig । Cadafalch, J., "Una tasca de civilizatció a realitzar per la Mancomunitat de Catalunya" (conferencia del 15 de diciembre de 1920), La Veu de Catalunya del día 16, el autor a la sazón era presidente del organismo catalán. Vid. Jardi, E., Puig i Cadafalch. Barcelona, Ariel, 1975

${ }^{68} \mathrm{Vid}$. Casassas, J., "La "Junta d'Afirmació Catalana" i la seva significació (1914-1917"), L'Avenç 39 (1981), págs. 58-61. 
"Comité d'Amics de la Unitat Moral d'Europa" (inspirado por d'Ors en Barcelona), así como todas aquellas manifestaciones que la intelectualidad pudo aprovechar, de entre el clima general de euforia, compromiso, movilización y controversia que generó el choque entre aliadófilos y germanófilos ${ }^{69}$.

La reacción frente a esta nueva situación general de emergencia va a traducirse igualmente en una necesidad de revisar las estrategias políticas anteriores, las que, como se recuerda ahora explícitamente, tienen su origen en la formulación positiva realizada en las Bases de Manresa de $1892^{70}$. Ello vendrá favorecido, secundariamente, por el recambio generacional que promueven las muertes de Torres i Bages, Marti i Julià, Prat de la Riba y N. Verdaguer i Callis entre 1916 y $1918^{71}$. Y va a concentrarse en la revolución política de la vieja Unió Catalanista, en una línea de síntesis entre socialismo y nacionalismo que influiría en la creación de la Unió Socialista de Cataluña en 1923 (pequeño partido de unas marcadas raices intelectuales y profesionales) ${ }^{72}$; también en los intentos de revitalización del republicanismo catalanista protagonizados por otro intelectual y destacado teórico del nacionalismo, A. Rovira Virgili, con una Esquerra Catalanista (1914); y, finalmente, con la aparición de una tendencia revisionista en el seno de la propia Lliga, progresivamente distanciada del cambonismo, al que consideran - con razón o sin ella- demasiado implicado en el pleito político español y en la creación de un partido de los industriales catalanes; ello es, con posturas generadoras de conflicto en la Cataluña de los años de postguerra ${ }^{73}$.

El personal que protagonizaba este tipo de actuaciones y las citadas más arriba se alineaba en el mismo sector intelectual-profesional. Por ello

\footnotetext{
69 Una visión reciente de este catalanismo que aprovecha la tensión social y cultural provocada por la guerra puede verse en, "El catalanisme i la Gran Guerra (1914-1918). Antologia" (a cura de D. Maratínez Fiol), Biblioteca dels Clàssics del Nacionalisme Català 21. Barcelona 1988.

${ }^{70}$ Este es el argumento de la conferencia inicial de las actividades de la Junta d'Afirmació Catalana dada por Josep Carner en el local del Centre Regionalista de Sarrià, "L'Affirmació Catalana" (6 de febrero de 1915).

"Vid. (RoRIVA I VIRGILI), "Any 1917. Necrològiques", Anuari de Catalunya 1917. Barcelona, Minerva, 1918, págs. 217-275 y 278-284

72 Vid. Dolors CAPDevila, M.-MASGRau, Roser, "La justicia social». Órguen de la Federació Catalana del PSOE (1910-1916). Barcelona, Centre d'Estidis d'Història Contemporània, 1979; MOLAS, I., "Federació Democràtica Nacionalista (1919-1923"), Recerques 4 (1974), págs. 137153; MARTin, J. I., «La Unió Socialista de Catalunya (1923-1936"), Recerques (ldem); Rodes, J. M. "Socialdemocràcia catalana i qüestió nacional (1910-1934»), Recerques 7 (1978), págs. 125-143.

${ }^{73}$ Vid. Baras, M., Acció Catalana (1922-1936). Barcelona, Curial, 1984
} 
no es de extrañar que uno de los frentes en que más va a implicarse sea en el de la defensa política de la labor burocrática, institucional y corporativa concebida por el novecentismo, labor cultural-nacional y al tiempo labor técnica y profesional que intentan llevar adelante con un talante moderno casi sorprendente. La elección de diputados para la Mancomunidad, en 1919, va a convertirse en un verdadero plebiscito que sanciona estas posturas al tiempo que las personifica en el viejo novecentismo, orsiano y pratiano a un tiempo, J. Bofill i Matas ${ }^{74}$. En los homenajes que van a tributársele de forma inmediata están implícitos todos los principios, y se reflejan todas las inquietudes del sector. A nadie extrañará que el propio Bofill se constituya en el principal acusador de Xénius en el "proceso» público, sectorial, político, intelectual y burocrático que se le aplica en 1920 y que precipita la marcha del "glosador» hacia Madrid $^{75}$. Finalmente, a nadie extrañará que este Bofill sea, a partir de noviembre de 1921, uno de los artífices del proceso que en junio de 1922 desembocará en la creación de Acció Catalana, agrupación política que identifica a la perfección estas inquietudes del sector intelectual-profesional catalán ante los cambios políticos y estructurales que identifican el área barcelonesa-catalana tras la Gran Guerra ${ }^{76}$.

La indefinición estratégica va a ser la nota dominante de los primeros pasos de esta Acció Catalana, a la que los contradictores denominaron como la "Lligueta", porque con el diminutivo aludían a la condición de director de la Juventud Nacionalista de la Lliga que había caracterizado a Bofill y Matas, líder de la nueva formación, a la que indirectamente degradaban a simple remedo descafeinado del partido regionalista ${ }^{77}$. Acció Catalana se autotitulará expresamente como una "formación de jóvenes patriotas", respuesta a la convicción de que debía reaccionarse ante el «desbordamiento colectivo» provocado por la guerra, sin prepotencias, y con el convencimiento de que el catalanismo aún se hallaba, según se decía, en «fase adolescente».

${ }^{74}$ Vid. BofILl, J., "Les Joventuts Catalanes" (14 de julio de 1919), en Una politica $i$ altres escrits (a cura de M. Baras), Biblioteca dels Clàssics del Nacionalisme Català 15. Barcelona 1986. Debe destacarse cómo la presentación del conservador Bofill corrió a cargo del socialista R. Campalans.

75 Vid. (J. Murgades), d'ORs, E., Glossari. Barcelona, Ed. 62, 1982; JaRdi, E., Eugeni d'Ors. Barcelona, Aymà, 1967; Díaz-PlAJA, G., La defenstració de Xènius. Andorra la Vella 1967.

${ }^{76}$ El paso de la dictadura primoriverista aun reforzará el protagonismo de las elites intelectuales en la dirección del grupo-partido. Con todo, los Estatus de Acció Catalana de 1922 preveían diez comisiones o secciones: organización y propaganda, profesorado, profesiones liberales, profesiones artísticas, estudiantes, campesinos, obreros, industria, comercio, deportes.

77 Vid. Pla, J., "Catalanisme i burgesia (notes de crítica política"), Revista de Catalunya 2 (agosto de 1924), págs. 125-135; de hecho este criticismo motivará su Cambó. Materials per a una història d'aquests últims anys. Barcelona, Catalònia, 1928 y 1929 (2 vols.). 
Así pues, se trataba del paso definitivo a la acción de un sector social que se había ido sintiendo forzado tanto por la evolución intelectual y política generales como por los no menos generales efectos producidos por el crecimiento y la transformación urbanas. Una acción en la que combinaban los postulados novecentistas, en que se habian formado políticamente, con otras sensibilidades que consideran reflejo fiel de la época, compatibles con el nuevo elitismo intelectual defensivo que va extendiéndose: un cierto cuestionamiento del parlamentarismo y del sistema de partidos heredados, la incorporación de elementos "socializantes" y la exacerbación de un sentimiento nacionalista que quieren convertir en elemento básico de cohesión social en época de crisis. Progresivamente se verá conectado con los vanguardismos e irracionalismos de postguerra $^{78}$, pero sin perder contactos reales con sectores de la sociedad y con instituciones públicas y privadas. Esta propuesta nacionalista de época de crisis, dará una visión más plural y acabada de la no-vertebración de España; además, la tradición reivindicativa del catalanismo le va a conferir un halo de insumisión frente al estado en decadencia muy en sintonía con los parámetros cultural-políticos europeos de la época, y que la acción represiva de la dictadura sólo hará que acrecentar ${ }^{79}$.

Las sintonías intelectuales con grupos castellanos es tan evidente como que a la postre no pudo hallarse un punto bien definido de colaboración política. En la vertebración del nacionalismo realizada por los intelectuales y profesionales catalanes sigue prevaleciendo, en equilibrio precario, la yuxtaposición de una aspiración de sintonizar con Europa a través de la cuestión de las nacionalidades; de una voluntad política de aportar una estrategia a la "formación" de España; y de la necesidad de hallar una moralidad colectiva que les sirviese para moverse en este difícil y tenso proceso por el que Barcelona se convierte en una moderna sociedad de masas, con todo el cúmulo de tensiones, desequilibrios y desigualdades que ello implicaba ${ }^{80}$.

\footnotetext{
${ }^{78}$ Resulta fundamental y novedoso el ensayo de UCELAY DA CAL, E., “Vanguardia, fascismo y la interacción entre nacionalismo español y catalán: el proyecto catalán de E. Giménez Caballero y algunas ideas corrientes en los círculos intelectuales de Barcelona (1927-1933"), ponencia en Os Nacionalismos na Segunda República (1931-1939). La Coruña septiembre-octubre de 1988 .

79 Vid. UCelay da Cal, E., La Catalunya populista, op. cit., cap. IIt.

${ }^{80}$ La colaboración política se acentuará a partir de marzo de 1930. Los intelectuales-políticos del catalanismo intentarán vertebrarla políticamente en el viaje de Rovira i Virgili y J. Bofill para visitar al Comité Revolucionario encarcelado en Madrid (febrero de 1931). Vid. CSASSAS, J., Jaume Bofill i Mates (1878-1933), op. cit., págs. 326-346
} 